\title{
Influence of sleep-wake cycle on body mass index in female shift-working nurses with sleep quality as mediating variable
}

\author{
Wen-Pei CHANG ${ }^{1,2 *}$ and Ching-Mei YANG ${ }^{2}$ \\ ${ }^{1}$ School of Nursing, College of Nursing, Taipei Medical University, Taiwan \\ ${ }^{2}$ Department of Nursing, Shuang Ho Hospital, Taipei Medical University, Taiwan \\ Received April 28, 2019 and accepted September 20, 2019 \\ Published online in J-STAGE October 1, 2019
}

\begin{abstract}
This study investigated the relationship between the sleep-wake cycle and body mass index (BMI) of female shift-working nurses and examine the mediating effect of sleep quality on this relationship. We recruited a total of 147 female nurses working monthly rotating shifts at a teaching hospital in Taiwan from the day $(n=63)$, evening $(n=50)$, and night $(n=34)$ shifts. Our research instruments utilized a questionnaire to collect demographic and work-related information, the Pittsburgh Sleep Quality Index (PSQI), and actigraphs to record sleep patterns for seven consecutive days. The sleep-wake cycles were then estimated using the dichotomy index $(I<O)$. The $\mathrm{I}<\boldsymbol{O}$ values were negatively associated with both $\mathrm{BMI}(\boldsymbol{\beta}=-\mathbf{0 . 2 8}, \boldsymbol{p}=\mathbf{0 . 0 0 1})$ and PSQI $\operatorname{scores}(\boldsymbol{\beta}=-\mathbf{0 . 2 9}$, $p<0.001$ ), the bootstrapping results indicated that the estimate of the indirect effect was -0.28 , and the $\mathbf{9 5 \%}$ confidence interval ranged from $-\mathbf{0 . 6 8}$ to $-\mathbf{0 . 0 5}$. For female shift-working nurses, sleep quality mediates the influence of the sleep-wake cycle on BMI, indicating that the maintenance of a regular sleep-wake cycle and good sleep quality could be important for female shift-working nurses.
\end{abstract}

Key words: Female, Shift-working nurse, Sleep-wake cycle, Body mass index, Sleep quality

\section{Introduction}

The worldwide prevalence of obesity has increased substantially in recent years, and overweight has become a major health issue ${ }^{1)}$. Obesity is the accumulation of excess body fat, and it cannot be determined based on body weight alone as height varies from person to person. The body mass index (BMI) is widely used as an indicator of body composition ${ }^{2)}$. Aside from indicating the severity of obesity, the BMI can also be used to investigate

*To whom correspondence should be addressed.

E-mail: 10479@s.tmu.edu.tw

(C)2020 National Institute of Occupational Safety and Health the correlation between obesity and other diseases ${ }^{3)}$. For female nurses, shift work is one of the risk factors of weight gain ${ }^{4)}$. Research has shown that shift workers are more likely to be overweight and have abnormal levels of triglyceride and high-density lipoprotein (HDL) cholesterol $^{5)}$.

There are many potential explanations for the link between shift work and obesity, including disruptions to circadian rhythms and sleep, which are explained in more detail below. Many physiological functions in the human body go through periodic changes that repeat roughly every $24 \mathrm{~h}$ and adjust according to time. These physiological cycles are called circadian rhythms, and these internal rhythmic mechanisms can be synchronized with light, particularly the sleep-wake cycle. However, the time of shift 
work can often conflict with the natural sleep-wake cycle of the body ${ }^{6}$. Circadian rhythms in the human body adjust very slowly, sometimes requiring days or even weeks. Thus, nurses who often rotate among different shifts experience irregular work hours as well as alterations to their sleep patterns and daily routines ${ }^{7)}$. Shift work often prevents internal physiological processes and rhythms from aligning correctly with external stimuli, thereby leading to a string of physical and mental issues. Shift work is therefore known to contribute to poor sleep and is a risk factor for several sleep disorders. Poor sleep in turn has a number of implications for employee health and wellbeing (e.g., increased risk of occupational accidents), and has been linked to overweight and obesity ${ }^{8}$.

Epidemiological studies have also established connections between inadequate sleep and increased risk of obesity. Aside from improper eating habits and a lack of exercise, poor sleep quality is also loosely associated with obesity $^{9,10)}$. The meta-analysis conducted by Fatima, Doi, and Mamun assessed the influence of poor sleep quality on young overweight and obese individuals. The results derived from 26,553 young individuals indicated that individuals who did not get enough sleep (including short sleep durations and poor sleep quality) were 1.27 times more likely to have overweight and obesity problems than those who did get enough sleep (Odds ratio $=1.27,95 \%$ Confidence interval: 1.24-1.72). A subsequent sub-group analysis also revealed that individuals with poor sleep quality were 1.46 times more likely to have overweight and obesity problems than those with good sleep quality (Odds ratio $=1.46,95 \%$ Confidence interval: $1.24-1.72)^{11}$. $\mathrm{Wu}$, Zhai, and Zhang conducted a meta-analysis on 11 prospective studies regarding the relationship between sleep duration and obesity. The studies involved a total of 197,906 individuals with shorter sleep durations and 164,016 individuals with longer sleep durations. They found that the risk of obesity in individuals with shorter sleep durations was 1.45 times higher than that in individuals with normal sleep durations $(95 \%$ Confidence interval: 1.25-1.67). Those with longer sleep durations and those with normal sleep durations presented no significant differences in future risk of obesity ${ }^{12}$. The studies above also suggested that a complex relationship may exist between sleep and the human metabolism and that sleep may play a crucial role in weight homeostasis.

In support, numerous studies have presented that age, marital status, educational background, years of service, and shift type are associated with the sleep-wake cycle, sleep quality, and BMI. Aging is connected to a decline in sleep quality as well as a gradual shortening of the deep sleep period ${ }^{13)}$. BMI is not only associated with age but also the level of education a person attains ${ }^{14)}$. A link between changes in marital status and changes in BMI was identified in a study by the Women's Health Initiative (WHI) that analyzed data obtained from approximately 79,000 women $^{15)}$. Griep et al. investigated 2,372 nurses at 18 hospitals and found a correlation between years of service and BMI, particularly among nurses working the night shift ${ }^{16)}$. Therefore, we included age, marital status, educational background, years of service, and shift type as background variables in this study and investigated whether the sleep-wake cycle, sleep quality score, and BMI of nurses vary with these background variables.

The objective of this study was to investigate whether sleep quality linked sleep-wake cycle with BMI in nurses. Drawing on previous research, it is plausible that nurses may affect their sleep-wake cycles or sleep quality. In investigating the links among shift work, sleep, and BMI, it is important to control for a range of covariates. In the present study we focused on the sleep-wake cycles of female shift nurses are correlated to their sleep quality and BMI. Based on studies involving sleep-wake cycles, sleep quality, and BMI, we formulated the hypotheses and research framework (Fig. 1) of this study:

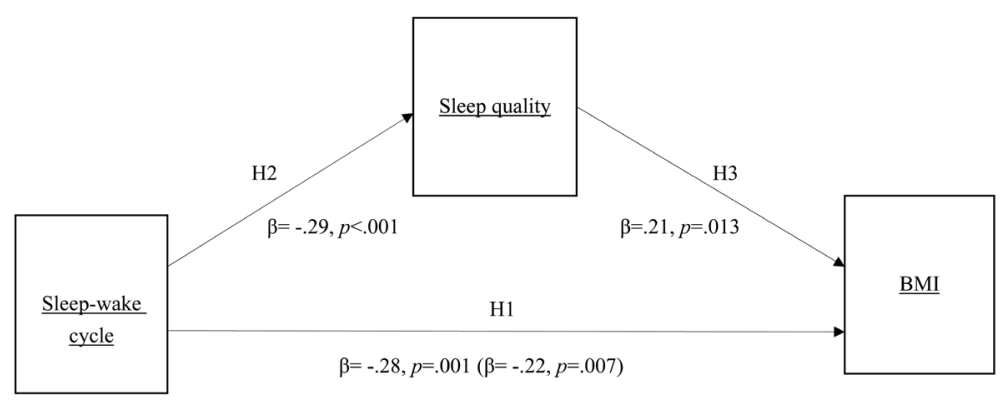

Fig. 1. Research framework and mediation path of the indirect influence of $\mathrm{I}<\mathrm{O}$ on $\mathrm{BMI}$ via sleep quality (coefficients in parentheses are coefficients of influence of independent variable on dependent variable in mediation model). 
H1: A more disturbed sleep-wake cycle is associated with higher BMI

H2: A more disturbed sleep-wake cycle is associated with poorer sleep quality

H3: In circumstances with more disturbed sleep-wake cycles, poorer sleep quality is associated with higher BMI

\section{Subjects and Methods}

\section{Study design}

The investigated population was comprised of female shift nurses working monthly shift rotations at a teaching hospital in Taiwan. Ethics approval was received from the Institutional Review Board (IRB) before any information was collected or analyzed. The approval number from the Office of Human Research, Taipei Medical University is N201708013. Ethics approval had been received from the Institutional Review Board (IRB) before Using purposive sampling, we recruited from January to December of 2018. Our targets were licensed nurses between the ages of 20 and 40 working shifts in ICU wards, surgical wards, and internal medicine wards. Pregnant nurses and nurses who had been diagnosed with obstructive sleep apnea (OSA) were excluded. Following approval from the institutional review board, we explained the objectives and methods to the participants and gained their written consent. A week after the nurses changed shifts, we conducted face-to-face interviews with them and they filled out a questionnaire in order for us to obtain their basic demographics and the Pittsburgh Sleep Quality Index (PSQI); under research tools were height and weight both self-reported. A sleep diary was used along with an actigraph, and the nurses were asked to also record their sleeping and waking times immediately after they woke up.

\section{Research tools}

The research questionnaire contained two parts. The first part involved collecting the basic demographics of the participants, including age, marital status, educational background, years of service, and shift type. Their BMI was calculated by dividing their weight $(\mathrm{kg})$ by their height $(\mathrm{m})$ squared. The second part of the questionnaire assessed their sleep conditions using the PSQI ${ }^{17)}$, which consists of 19 question items and seven component scores regarding subjective sleep quality, sleep latency, sleep duration, sleep efficiency, sleep disturbances, sleeping medication, and daytime dysfunction. Each component score ranges from 0 to 3 points; therefore, the total score ranges from 0 to 21 points, with a higher score indicating poorer sleep quality; total PSQI scores equaling 5 points or higher were indicative of poor sleep quality. The internal consistency of the questionnaire presented a Cronbach's $\alpha$ of 0.83 with a test-retest reliability of 0.85 a month later ${ }^{17)}$. The Cronbach's $\alpha$ of the translated version for Taiwan is 0.79 , with a test-retest reliability of $0.91^{18)}$. The Cronbach's $\alpha$ of the PSQI questionnaire in this study was 0.70 .

The sleep-wake cycle has an almost one-to-one correlation with the rest-activity cycle, and changes in the amount of activity are associated with the changes in muscle tone in different sleep stages. Thus, the sleep-wake status of participants can be indirectly measured via special instruments that detect activity levels. We therefore utilized a widely used actigraph (Ambulatory Monitoring Inc., NY, USA) to measure sleep-wake cycles. An actigraph is a watch-like recording device that uses an accelerometer to detect the changes in the activity levels of the participant and the muscle tone changes in various sleep stages, and then quantifies and stores the changes. A complete assessment of a participant's sleep-wake rhythms can be made without affecting normal routines. Thus, an actigraph is more suitable for long-term sleep-wake cycle monitoring than polysomnography, which measure brain waves, and serves as an extremely valid tool for collecting data on sleep-wake cycles ${ }^{19)}$. The actigraph was then linked to Action-4 software on a computer for data analysis. Once we downloaded the data using the zero-crossing mode $(\mathrm{ZCM})^{20)}$, we estimated the sleep-wake cycles using the dichotomy index $(\mathrm{I}<\mathrm{O})$ to divide the daily physical activity data into active periods and non-active periods. This means that the activity level during sleep periods is lower than the median percentage of that during awake periods; $100 \%$ indicates that the sleep period is uninterrupted, and lower $\mathrm{I}<\mathrm{O}$ values mean greater disruptions in the sleepwake cycle. In this way, we could objectively measure the interdaily stability of sleep and activity ${ }^{21,22)}$. We supplemented the data with self-kept sleep logs, in which the participants were required to recall and record when they went to bed and when they woke up every morning for seven consecutive days. The sleep logs and the actigraph data helped increase the accuracy of the $\mathrm{I}<\mathrm{O}$ values derived from software analysis ${ }^{23}$.

\section{Statistical analyses}

Using IBM SPSS 22.0 (SPSS, Chicago, IL, USA), we first conducted independent sample $t$ tests and one-way ANOVAs to determine whether the $\mathrm{I}<\mathrm{O}$ value, $\mathrm{PSQI}$ score, and BMI varied with different types of nurses. In the event that the F statistic of a one-way ANOVA reached the level 
of significance $(\alpha=0.05)$, we then performed a post hoc comparison using Scheffé's method. We also conducted simple regression analysis to examine the relationships among them. Next, we used mediated hierarchical regression analysis to verify whether PSQI scores had a mediating effect with $\mathrm{I}<\mathrm{O}$ values as the predictor variable and BMI as the outcome variable. We used IBM SPSS 22.0 and the MACRO-PROCESS v2.16 developed by Hayes for analysis. In the PROCESS interface, we selected the mediation model for analysis. We also verified the significance of the mediation effect using bootstrapping. With 1,000 repeated samples, we constructed the bias-corrected confidence interval of the indirect effect. If the $95 \%$ confidence interval does not cover 0 , then the indirect effect is significant and the hypothesis of the mediation effect is supported $^{24)}$.

\section{Results}

\section{Basic attributes of female shift nurses}

We recruited a total of 147 female nurses working monthly rotating shifts: 63 day-shift nurses, 50 eveningshift nurses, and 34 night-shift nurses. As shown in Table 1, the majority of the participants (125 nurses) were between

Table 1. Basic attributes of female shift nurses $(N=147)$

\begin{tabular}{|c|c|c|}
\hline Basic information & $\mathrm{N}$ & $\%$ \\
\hline \multicolumn{3}{|l|}{ Age } \\
\hline $21-30 \mathrm{yr}$ & 125 & 85 \\
\hline $31-40 \mathrm{yr}$ & 22 & 15 \\
\hline \multicolumn{3}{|l|}{ Marital status } \\
\hline Single & 137 & 93.2 \\
\hline Married & 10 & 6.8 \\
\hline \multicolumn{3}{|l|}{ Educational background } \\
\hline Junior college & 64 & 43.5 \\
\hline University or above & 83 & 56.5 \\
\hline \multicolumn{3}{|l|}{ Years of service } \\
\hline$<2 \mathrm{yr}$ & 51 & 34.7 \\
\hline $2-5 \mathrm{yr}$ & 48 & 32.7 \\
\hline$>5 \mathrm{yr}$ & 48 & 32.7 \\
\hline \multicolumn{3}{|l|}{ Shift type } \\
\hline Day & 63 & 42.9 \\
\hline Evening & 50 & 34 \\
\hline \multirow[t]{2}{*}{ Night } & 34 & 23.1 \\
\hline & Mean & $\mathrm{SD}$ \\
\hline $\mathrm{I}<\mathrm{O}(\%)$ & 99.05 & 1.08 \\
\hline PSQI score & 7.05 & 3.07 \\
\hline BMI $\left(\mathrm{kg} / \mathrm{m}^{2}\right)$ & 26.6 & 5.01 \\
\hline
\end{tabular}

$\mathrm{I}<\mathrm{O}$ : dichotomy index; PSQI: Pittsburgh Sleep Quality Index; BMI: body mass index. the ages of 21 and 30 , accounting for $85.0 \%$ of the sample population. The greater majority of the participants (137 nurses) were single, occupying $93.2 \%$ of the sample population. Over half of the participants ( 83 nurses) had a bachelor's degree or higher, accounting for $56.5 \%$ of the sample population. For years of service, the largest group (51 nurses) had served for less than $2 \mathrm{yr}$, occupying $34.7 \%$ of the sample population. The mean $\mathrm{I}<\mathrm{O}$, PSQI score, and BMI were $99.05(S D=1.08), 7.05(S D=2.07)$, and $26.60 \mathrm{~kg} /$ $\mathrm{m}^{2}(S D=5.01)$, respectively. The standard deviation of $\mathrm{I}<\mathrm{O}$ was less than those of the other variables, which means that the sleep-wake cycles of the nurses working the three shifts did not vary significantly. Figure 2 displays representative sleep-wake cycles derived from the actigraphs worn by nurses in three different shifts.

Differences in sleep-wake cycle, sleep quality, and BMI among different shift nurses

As shown in Table 2, $t$-tests presented significant differences in the sleep-wake cycle with regard to age $(t=2.238, p=0.035)$ and educational background $(t=-2.141$, $p=0.045)$. The $F$ statistic of the $\mathrm{I}<\mathrm{O}$ values for the shift worked was significant ( $F=6.781, p=0.002)$; therefore, we performed a post hoc comparison, which revealed that the $\mathrm{I}<\mathrm{O}$ values of the day-shift $(M \pm S D=99.13 \pm 0.99)$ and evening-shift $(M \pm S D=99.32 \pm 0.87)$ nurses were significantly higher than those of the night-shift nurses $(M$ $\pm S D=98.50 \pm 1.31$ ). In contrast, the PSQI scores and BMI of the nurses did not vary significantly with age, marital status, educational background, or years of service.

\section{Influences of sleep-wake cycle on sleep quality and of} sleep quality on $B M I$

With the unadjusted background variables, Table 3 indicates that $\mathrm{I}<\mathrm{O}$ values were negatively associated with PSQI scores ( $\beta=-0.29,95 \% \mathrm{CI}:-1.28$ to -0.37 ). With the adjusted background variables, a significant and negative correlation still existed between $\mathrm{I}<\mathrm{O}$ and PSQI scores $(\beta=-0.26,95 \%$ CI: -1.24 to -0.23$)$.

In addition, as shown with the unadjusted background variables in Table 4, PSQI scores exerted a significant and positive association with BMI $(\beta=0.27,95 \% \mathrm{CI}$ : $0.18-0.70)$. After the background variables were adjusted, a significant and positive correlation still existed between the PSQI scores and BMI ( $\beta=0.20,95 \%$ CI: $0.06-0.59)$.

Analysis of indirect paths of sleep quality on influence of sleep-wake cycle on BMI

Table 4 displays the test results. With the unadjusted 


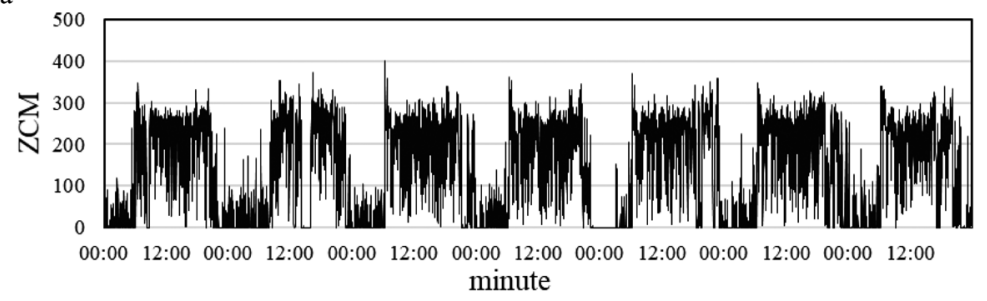

b
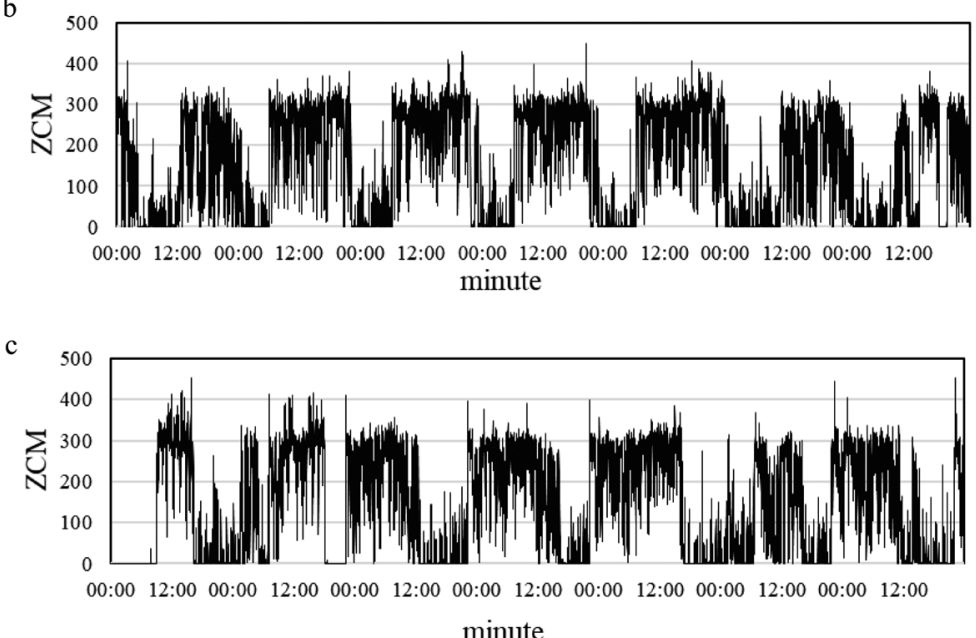

Fig. 2. Sleep-wake cycles from actigraphs worn by female nurses in three different shifts for seven consecutive days. (a) regular sleep-wake cycle $(\mathrm{I}<\mathrm{O}=99.42 \%)$ of a 34-yr-old day-shift nurse with a BMI of $31.20\left(\mathrm{~kg} / \mathrm{m}^{2}\right)$; (b) regular sleepwake cycle $(\mathrm{I}<\mathrm{O}=99.89 \%)$ of a 22 -yr-old evening-shift nurse with a BMI of $24.20\left(\mathrm{~kg} / \mathrm{m}^{2}\right)$; (c) irregular sleep-wake cycle $(\mathrm{I}<\mathrm{O}=97.92 \%)$ of a 24 -yr-old night-shift nurse with a BMI of $24.80\left(\mathrm{~kg} / \mathrm{m}^{2}\right)$.

Table 2. Analysis of differences in BMI, sleep quality, and sleep-wake cycle among nurses with different attributes $(N=147)$

\begin{tabular}{|c|c|c|c|c|c|c|c|c|c|c|c|c|c|c|}
\hline \multirow{2}{*}{$\begin{array}{c}\text { Basic } \\
\text { attributes }\end{array}$} & \multirow[b]{2}{*}{ Group } & \multicolumn{5}{|c|}{$\mathrm{I}<\mathrm{O}$} & \multicolumn{4}{|c|}{ PSQI score } & \multicolumn{4}{|c|}{ BMI } \\
\hline & & Mean & SD & $F / t$ & $p$ & $\begin{array}{l}\text { Scheffe's } \\
\text { post hoc }\end{array}$ & Mean & $\mathrm{SD}$ & $F / t$ & $p$ & Mean & SD & $F / t$ & $p$ \\
\hline \multirow[t]{2}{*}{ Age } & $21-30 \mathrm{yr}$ & 99.16 & 0.94 & 2.238 & 0.035 & & 6.98 & 3.15 & -0.597 & 0.551 & 23.47 & 5.03 & -1.047 & 0.297 \\
\hline & $31-40 \mathrm{yr}$ & 98.41 & 1.52 & & & & 7.41 & 2.61 & & & 24.68 & 4.88 & & \\
\hline \multirow{2}{*}{$\begin{array}{l}\text { Marital } \\
\text { status }\end{array}$} & Single & 98.86 & 1.28 & -0.553 & 0.581 & & 7.1 & 3.11 & -0.797 & 0.427 & 23.75 & 5.12 & -0.868 & 0.387 \\
\hline & Married & 99.06 & 1.06 & & & & 6.3 & 2.45 & & & 22.32 & 3.17 & & \\
\hline \multirow{2}{*}{$\begin{array}{l}\text { Educational } \\
\text { background }\end{array}$} & Junior college & 98.83 & 1.3 & -2.141 & 0.045 & & 7.47 & 3.28 & 1.466 & 0.145 & 24.32 & 5.45 & 1.419 & 0.158 \\
\hline & University or above & 99.21 & 0.83 & & & & 6.72 & 2.88 & & & 23.14 & 4.62 & & \\
\hline \multirow{3}{*}{$\begin{array}{l}\text { Years of } \\
\text { service }\end{array}$} & $<2 \mathrm{yr}$ & 99.31 & 0.87 & 2.587 & 0.079 & & 6.55 & 3.09 & 2.131 & 0.122 & 22.7 & 3.7 & 1.411 & 0.247 \\
\hline & $3-5 \mathrm{yr}$ & 98.97 & 1.08 & & & & 7.77 & 3.38 & & & 24.12 & 6.14 & & \\
\hline & $>5 \mathrm{yr}$ & 98.84 & 1.22 & & & & 6.85 & 2.62 & & & 24.19 & 4.93 & & \\
\hline \multirow[t]{3}{*}{ Shift type } & Day & 99.13 & 0.99 & 6.781 & 0.002 & Day, Evening & 7.05 & 2.96 & 0.984 & 0.376 & 23.31 & 4.96 & 0.691 & 0.503 \\
\hline & Evening & 99.32 & 0.87 & & & $>$ Night & 6.66 & 3.01 & & & 24.33 & 4.83 & & \\
\hline & Night & 98.5 & 1.31 & & & & 7.62 & 3.36 & & & 23.28 & 5.42 & & \\
\hline
\end{tabular}

$\mathrm{I}<\mathrm{O}$ : dichotomy index; PSQI: Pittsburgh Sleep Quality Index; BMI: body mass index.

background variables, the $\mathrm{I}<\mathrm{O}$ value was the predictor variable, and the BMI was the outcome dependent variable. The $\beta$ value of the $\mathrm{I}<\mathrm{O}$ value in this model was -0.28
(95\% CI: -2.06 to -0.58$)$. After the background variables were adjusted, the $\mathrm{I}<\mathrm{O}$ value and the PSQI score served as predictor variables at the same time, while the BMI was 
Table 3. Regression coefficients of influence of parameters of sleep-wake cycle on sleep quality $(N=147)$

\begin{tabular}{|c|c|c|c|c|c|c|}
\hline \multirow{2}{*}{ Variable } & \multicolumn{3}{|c|}{ Unadjusted } & \multicolumn{3}{|c|}{ Adjusted } \\
\hline & $\beta$ & $95 \% \mathrm{CI}$ & $p$ & $\beta$ & $95 \% \mathrm{CI}$ & $p$ \\
\hline \multicolumn{7}{|l|}{ Age } \\
\hline $21-30 \mathrm{yr}$ & & Reference & & & Reference & \\
\hline $31-40 \mathrm{yr}$ & 0.05 & -0.98 to 1.83 & 0.551 & 0.06 & -1.20 to 2.29 & 0.536 \\
\hline \multicolumn{7}{|l|}{ Marital status } \\
\hline Single & & Reference & & & Reference & \\
\hline Married & 0.07 & -1.19 to 2.79 & 0.797 & 0.08 & -1.21 to 3.13 & 0.382 \\
\hline \multicolumn{7}{|l|}{ Educational background } \\
\hline Junior college & & Reference & & & Reference & \\
\hline University or above & -0.12 & -1.75 to 0.26 & 0.145 & -0.05 & -1.36 to 0.78 & 0.593 \\
\hline \multicolumn{7}{|l|}{ Years of service } \\
\hline$<2 \mathrm{yr}$ & & Reference & & & Reference & \\
\hline $2-5 \mathrm{yr}$ & 0.19 & 0.01 to 2.43 & 0.048 & 0.14 & -0.29 to 2.14 & 0.133 \\
\hline$>5 \mathrm{yr}$ & 0.05 & -0.91 to 1.52 & 0.619 & -0.02 & -1.62 to 1.38 & 0.877 \\
\hline \multicolumn{7}{|l|}{ Shift type } \\
\hline Day & & Reference & & & Reference & \\
\hline Evening & -0.06 & -1.54 to 0.76 & 0.506 & -0.05 & -1.48 to 0.85 & 0.597 \\
\hline Night & 0.08 & -0.72 to 1.86 & 0.385 & -0.01 & -1.45 to 1.28 & 0.903 \\
\hline $\mathrm{I}<\mathrm{O}$ & -0.29 & -1.28 to 0.37 & $<0.001$ & -0.26 & -1.24 to -0.23 & 0.004 \\
\hline
\end{tabular}

$\beta$ : standardized regression coefficient; $\mathrm{CI}$ : confidence interval; $\mathrm{I}<\mathrm{O}$ : dichotomy index.

Table 4. Regression coefficients of influence of parameters of sleep-wake cycle and sleep quality on BMI $(N=147)$

\begin{tabular}{|c|c|c|c|c|c|c|}
\hline \multirow{2}{*}{ Variable } & \multicolumn{3}{|c|}{ Unadjusted } & \multicolumn{3}{|c|}{ Adjusted } \\
\hline & $\beta$ & $95 \% \mathrm{CI}$ & $p$ & $\beta$ & $95 \% \mathrm{CI}$ & $p$ \\
\hline \multicolumn{7}{|l|}{ Age } \\
\hline $21-30 \mathrm{yr}$ & & Reference & & & Reference & \\
\hline $31-40 \mathrm{yr}$ & 0.09 & -1.08 to 3.50 & 0.297 & 0.01 & -2.59 to 2.90 & 0.913 \\
\hline \multicolumn{7}{|l|}{ Marital status } \\
\hline Single & & Reference & & & Reference & \\
\hline Married & 0.07 & -1.82 to 4.68 & 0.387 & 0.13 & -0.87 to 5.95 & 0.142 \\
\hline \multicolumn{7}{|l|}{ Educational background } \\
\hline Junior college & & Reference & & & Reference & \\
\hline University or above & -0.12 & -2.82 to 0.46 & 0.158 & -0.12 & -2.85 to 0.52 & 0.173 \\
\hline \multicolumn{7}{|l|}{ Years of service } \\
\hline$<2 \mathrm{yr}$ & & Reference & & & Reference & \\
\hline $2-5 \mathrm{yr}$ & 0.13 & -0.56 to 3.41 & 0.159 & 0.1 & -0.83 to 2.97 & 0.283 \\
\hline$>5 \mathrm{yr}$ & 0.14 & -0.56 to 3.47 & 0.142 & 0.22 & 0.01 to 4.71 & 0.049 \\
\hline \multicolumn{7}{|l|}{ Shift type } \\
\hline Day & & Reference & & & Reference & \\
\hline Evening & 0.1 & -0.86 to 2.90 & 0.286 & 0.14 & -0.31 to 3.36 & 0.103 \\
\hline Night & -0.01 & -2.14 to 2.90 & 0.98 & -0.15 & -3.86 to 0.41 & 0.112 \\
\hline $\mathrm{I}<\mathrm{O}$ & -0.28 & -2.06 to 0.58 & 0.001 & -0.24 & -1.94 to 0.32 & 0.007 \\
\hline PSQI score & 0.27 & 0.18 to 0.70 & 0.001 & 0.2 & 0.06 to 0.59 & 0.016 \\
\hline
\end{tabular}

$\beta$ : standardized regression coefficient; CI: confidence interval; $\mathrm{I}<\mathrm{O}$ : dichotomy index; PSQI: Pittsburgh Sleep Quality Index.

the dependent variable. The $\beta$ value of the $\mathrm{I}<\mathrm{O}$ value was -0.24 (95\% CI: -1.94 to -0.32 ). Furthermore, the bootstrapping results indicated that the estimate of the indirect effect was -0.28 , and the $95 \%$ confidence interval ranged from -0.68 to -0.05 . The confidence interval did not cover 0 , which means that using bootstrapping to test the media- 
tion effect of the PSQI scores was also supported. Figure 1 clearly displays the mediation path of the indirect influence of $\mathrm{I}<\mathrm{O}$ on BMI via sleep quality.

\section{Discussion}

The results above demonstrate that female shift nurses who were between the ages of 21 and 30, had a bachelor's degree or higher, or were working the day or evening shifts had better sleep-wake cycles than those who were between the ages of 31 and 40, had a junior college degree, or were working the night shift. The $\mathrm{I}<\mathrm{O}$ value is associated with BMI as well as the PSQI score. The PSQI score had an indirect effect on the $\mathrm{I}<\mathrm{O}$ value on $\mathrm{BMI}$.

The total PSQI scores of all of the nurses in this study were 5 points or higher, indicating poor sleep quality. These results were consistent with those derived by McDowall, Murphy, and Anderson, who had compared the sleep quality of shift and non-shift nurses and found that after controlling for age, gender, years of service, and other possible factors, non-shift nurses suffer 0.410 times fewer sleep issues than do shift nurses (odds ratio $=0.410)^{25}$. Poor sleep quality is also common among shift workers; they often complain of altered sleeping habits, difficulty falling asleep, or interrupted sleep ${ }^{26)}$. Thus, sleep disorders are indeed a severe problem for shift workers.

In terms of the relationship between sleep quality and BMI, this study found a positive correlation between poorer sleep quality and changes in BMI. Poor sleep quality may affect dietary choices; individuals suffering from sleep deprivation show a greater tendency to choose food or drink that are high in fat and sugar than those with normal sleep ${ }^{27)}$. Indeed, Prather et al. discovered that people who sleep less than six hours a day drink significantly more sugar-sweetened beverages than those who sleep seven to eight hours. More strikingly, those who sleep less than five hours consume even more sugar-sweetened beverages than those who sleep less than six $\mathrm{h}^{28)}$. Calvin et al. recruited 17 random young and healthy men and women for an eight-night investigation ${ }^{29)}$. Half of the participants were asked to maintain their normal sleep durations, while the other half were asked to sleep for two-thirds of their normal sleep durations. The results revealed altered leptin and ghrelin concentrations and increased appetite in the participants with inadequate sleep, which caused them to overeat and significantly increase their daily calorie intake $^{29)}$. Thus, disrupted sleep-wake cycles and poor sleep quality could feasibly lead to obesity in a number of ways, including via alterations in appetite regulation and eating behavior. Beccutim and Pannain further pointed out that sleep is an important moderator of neuroendocrine functions and glucose metabolism ${ }^{30)}$. Inadequate sleep alters metabolism and endocrines, such as reductions in insulin sensitivity and glucose tolerance, elevation of plasma cortisol levels during sleep, increases in auxin concentrations, and decreases in leptin concentrations, which in turn all contribute to the feeling of hunger and increased appetite $^{31)}$. Poor sleep quality may also affect the body's gene expression, which would impact all of the metabolic responses in the body ${ }^{30)}$. Thus, it suggests that sleep quality of humans is highly associated with the operation of physiological functions, whether it be appetite, blood sugar level, blood pressure, or BMI.

As for the relationship between sleep-wake cycle and BMI, this study found that shift-working nurses with greater irregularity in their sleep-wake cycles were at greater risk of increases in BMI. Moreover, impacts on the regularity of the biological rhythms in female shift nurses may be present. Shift work alters sleep schedules and meal times, which also dysregulates hormone produc$\operatorname{tion}^{28)}$. This facilitates the transport of ghrelin to the brain, which travels to the hypothalamus and increases appetite and food intake, thereby leading first to weight gain, then overweight, and finally obesity. Furthermore, this can exacerbate imbalances in hormone production, potentially causing metabolic disorders and increases the chance of developing metabolic syndromes ${ }^{32)}$.

In addition, to verify whether the mediation effect of sleep quality exists, we tested the mediating variables of sleep-wake cycle and BMI. The results of this study indicate that the mediation effect of sleep quality indeed exists, meaning sleep quality is a mediating variable between sleep-wake cycle and BMI. In other words, an irregular sleep-wake cycle is connected to increases in BMI via poor sleep quality. Although no studies have investigated the influence path of sleep-wake cycle on BMI via sleep quality, it is supported by some theories. The sleep-wake cycle of the human body follows daylight and night cycles. Adjusting one's sleep-wake cycle appropriately would definitely improve sleep quality because during sleep, the pineal gland in our brain secretes melatonin, which can regulate our biological clock and help our bodies sleep peacefully ${ }^{33)}$. At the same time, melatonin also influences the regulatory mechanisms of insulin secretion, affects insulin resistance, and is associated with metabolic syndrome and obesity. It is therefore not surprising that shift workers are more likely to have issues with obesity due to reductions in the melatonin concentration in the blood, 
which could lead to insulin resistance, glucose intolerance, and other metabolism-related changes ${ }^{34)}$. This supports our finding that sleep quality has a mediating effect on the relationship between the sleep-wake cycle and BMI.

\section{Limitations and future directions}

The $\mathrm{I}<\mathrm{O}$ values collected from the shift-working nurses in this study fell within a narrow range of $\mathrm{I}<\mathrm{O}$ values, which made it difficult to perceive any differences among different background variables. Furthermore, self-report data are subject to the influence of selective memory and exaggeration, thereby distorting the questionnaire results. The smaller number of samples in this study may also have affected the precision of the results. This demonstrates the significant correlations in the research content. Also, on account of the cross-sectional research design, the study results only present the correlation between variables and not the causal relationships. In another aspect, this study did not collect other important variables that may potentially influence sleep quality, sleep-wake cycle, or BMI, such as dietary habits, physical diseases, mental health, or exercise habits. These are the limitations of this study.

In addition, the participants in this study all comprised nurses who worked in a single medical center; therefore, our findings may not be applicable to nursing personnel who work in other medical institutions. Future studies that focus on nurses in other medical institutions and also investigate a greater number of subjects can help broaden the scope of research findings and increase the value of reference information. This study did not include nurses working fixed shifts as a control group. We suggest that future studies include such nurses to increase the accuracy of the study results.

\section{Conclusions}

For female shift nurses, sleep quality mediates the influence of the sleep-wake cycle on BMI. Thus, maintaining a regular sleep-wake cycle and good sleep quality could be important for a healthy body composition in female shiftworking nurses. These findings require confirmation in prospective studies, as such research could inform strategies to help female shift-working nurses maintain regular schedules, which in turn could benefit their sleep and body composition.

\section{Conflicts of Interest}

The authors have no conflict of interest to disclose.

\section{References}

1) World Health Organization Obesity and overweight. http:// www.who.int/mediacentre/factsheets/fs311/en/. Accessed September 17, 2018.

2) Darmasseelane K, Hyde MJ, Santhakumaran S, Gale C, Modi N (2014) Mode of delivery and offspring body mass index, overweight and obesity in adult life: a systematic review and meta-analysis. PLoS One 9, e87896. [Medline] [CrossRef]

3) Goldani HA, Bettiol H, Barbieri MA, Silva AA, Agranonik M, Morais MB, Goldani MZ (2011) Cesarean delivery is associated with an increased risk of obesity in adulthood in a Brazilian birth cohort study. Am J Clin Nutr 93, 1344-7. [Medline] [CrossRef]

4) Peplonska B, Bukowska A, Sobala W (2015) Association of rotating night shift work with BMI and abdominal obesity among nurses and midwives. PLoS One 10, e0133761. [Medline] [CrossRef]

5) Akbari H, Mirzaei R, Nasrabadi T, Gholami-Fesharaki $M$ (2015) Evaluation of the effect of shift work on serum cholesterol and triglyceride levels. Iran Red Crescent Med J 17, e18723. [Medline] [CrossRef]

6) Costa G (2010) Shift work and health: current problems and preventive actions. Saf Health Work 1, 112-23. [Medline] [CrossRef]

7) Marquezea EC, Lemosa LC, Soaresa N, Lorenzi-Filhob G, Morenoa CRC (2012) Weight gain in relation to night work among nurses. Work 41 Suppl 1, 2043-8. [Medline] [CrossRef]

8) Narciso FV, Barela JA, Aguiar SA, Carvalho ANS, Tufik S, de Mello MT (2016) Effects of shift work on the postural and psychomotor performance of night workers. PLoS One 11, e0151609. [Medline] [CrossRef]

9) Finucane MM, Stevens GA, Cowan MJ, Danaei G, Lin JK, Paciorek CJ, Singh GM, Gutierrez HR, Lu Y, Bahalim AN, Farzadfar F, Riley LM, Ezzati M, Global Burden of Metabolic Risk Factors of Chronic Diseases Collaborating Group (Body Mass Index) (2011) National, regional, and global trends in body-mass index since 1980: systematic analysis of health examination surveys and epidemiological studies with 960 country-years and 9.1 million participants. Lancet 377, 557-67. [Medline] [CrossRef]

10) Knutson KL (2010) Sleep duration and cardiometabolic risk: a review of the epidemiologic evidence. Best Pract Res Clin Endocrinol Metab 24, 731-43. [Medline] [CrossRef]

11) Fatima Y, Doi SA, Mamun AA (2016) Sleep quality and obesity in young subjects: a meta-analysis. Obes Rev 17, 1154-66. [Medline] [CrossRef]

12) Wu Y, Zhai L, Zhang D (2014) Sleep duration and obesity among adults: a meta-analysis of prospective studies. Sleep Med 15, 1456-62. [Medline] [CrossRef]

13) Mander BA, Winer JR, Walker MP (2017) Sleep and human aging. Neuron 94, 19-36. [Medline] [CrossRef]

14) Hayes A, Gearon E, Backholer K, Bauman A, Peeters A 
(2015) Age-specific changes in BMI and BMI distribution among Australian adults using cross-sectional surveys from 1980 to 2008. Int J Obes 39, 1209-16. [Medline] [CrossRef]

15) Kutob RM, Yuan NP, Wertheim BC, Sbarra DA, Loucks EB, Nassir R, Bareh G, Kim MM, Snetselaar LG, Thomson CA (2017) Relationship between marital transitions, health behaviors, and health indicators of postmenopausal women: results from the Women's Health Initiative. J Womens Health (Larchmt) 26, 313-20. [Medline] [CrossRef]

16) Griep RH, Bastos LS, Fonseca MJ, Silva-Costa A, Portela LF, Toivanen S, Rotenberg L (2014) Years worked at night and body mass index among registered nurses from eighteen public hospitals in Rio de Janeiro, Brazil. BMC Health Serv Res 14, 603 [CrossRef]. [Medline]

17) Buysse DJ, Reynolds CF 3rd, Monk TH, Berman SR, Kupfer DJ (1989) The Pittsburgh Sleep Quality Index: a new instrument for psychiatric practice and research. Psychiatry Res 28, 193-213. [Medline] [CrossRef]

18) Tzeng JI, Fu YW, Lin CC (2012) Validity and reliability of the Taiwanese version of the Pittsburgh Sleep Quality Index in cancer patients. Int J Nurs Stud 49, 102-8. [Medline] [CrossRef]

19) Madsen MT, Rosenberg J, Gögenur I (2013) Actigraphy for measurement of sleep and sleep-wake rhythms in relation to surgery. J Clin Sleep Med 9, 387-94. [Medline] [CrossRef]

20) Tahmasian M, Khazaie H, Sepehry AA, Russo MB (2010) Ambulatory monitoring of sleep disorders. J Pak Med Assoc 60, 480-7. [Medline]

21) Huang Q, Cohen D, Komarzynski S, Li XM, Innominato P, Lévi F, Finkenstädt B (2018) Hidden Markov models for monitoring circadian rhythmicity in telemetric activity data. J R Soc Interface 15, 20170885. [Medline] [CrossRef]

22) Natale V, Innominato PF, Boreggiani M, Tonetti L, Filardi M, Parganiha A, Fabbri M, Martoni M, Lévi F (2015) The difference between in bed and out of bed activity as a behavioral marker of cancer patients: a comparative actigraphic study. Chronobiol Int 32, 925-33. [Medline] [CrossRef]

23) Kawada $T$ (2013) Sleep parameters from actigraphy and sleep diary: is the agreement important for sleep study?
Sleep Med 14, 298-9. [Medline] [CrossRef]

24) Shrout PE, Bolger N (2002) Mediation in experimental and nonexperimental studies: new procedures and recommendations. Psychol Methods 7, 422-45. [Medline] [CrossRef]

25) McDowall K, Murphy E, Anderson K (2017) The impact of shift work on sleep quality among nurses. Occup Med (Lond) 67, 621-5. [Medline] [CrossRef]

26) Almeida CM, Malheiro A (2016) Sleep, immunity and shift workers: a review. Sleep Sci 9, 164-8. [Medline] [CrossRef]

27) Chapman CD, Nilsson EK, Nilsson VC, Cedernaes J, Rångtell FH, Vogel H, Dickson SL, Broman JE, Hogenkamp PS, Schiöth HB, Benedict C (2013) Acute sleep deprivation increases food purchasing in men. Obesity (Silver Spring) 21, E555-60. [Medline] [CrossRef]

28) Prather AA, Leung CW, Adler NE, Ritchie L, Laraia B, Epel ES (2016) Short and sweet: associations between self-reported sleep duration and sugar-sweetened beverage consumption among adults in the United States. Sleep Health 2, 272-6. [Medline] [CrossRef]

29) Calvin AD, Carter RE, Adachi T, Macedo PG, Albuquerque FN, van der Walt C, Bukartyk J, Davison DE, Levine JA, Somers VK (2013) Effects of experimental sleep restriction on caloric intake and activity energy expenditure. Chest 144, 79-86. [Medline] [CrossRef]

30) Beccuti G, Pannain S (2011) Sleep and obesity. Curr Opin Clin Nutr Metab Care 14, 402-12. [Medline] [CrossRef]

31) Leproult R, Van Cauter E (2010) Role of sleep and sleep loss in hormonal release and metabolism. Endocr Dev 17, 11-21. [Medline] [CrossRef]

32) Ulhôa MA, Marqueze EC, Burgos LGA, Moreno CRC (2015) Shift work and endocrine disorders. Int J Endocrinol 2015, 826249. [Medline] [CrossRef]

33) Waterhouse J, Fukuda Y, Morita T (2012) Daily rhythms of the sleep-wake cycle. J Physiol Anthropol 31, 5. [Medline] [CrossRef]

34) Broussard J, Brady MJ (2010) The impact of sleep disturbances on adipocyte function and lipid metabolism. Best practice \& research. J Clin Endocrinol Metab 4, 763-73. 